\title{
Two kinds of famillarization in tachistoscopic recognition, paired-associate learning, and free recall'
}

WILMA A. WINNICK, Queens College of the City University of New York, Flushing, N.Y. 11367

The effects of two different familiarization procedures were examined in three experimental situations. Tachistoscopic recognition thresholds were lowered for two groups which in pretraining had either made smaller words from the letters of experimental words or found associates for these words. In comparable groups, experimental words of both types lost their small initial advantage during the course of paired-associate learning. In free-recall learning, the group that had found associates for the experimental words started off with a first-trial advantage for these words greater than that for the group that had formed smaller words out of the experimental words; trials-to-criterion data showed that this advantage was finally lost.

It seems, from previous comparisons of the effect of the same variables upon tachistoscopic thresholds and verbal learning (e.g., Gibson, Bishop, Schiff, \& Smith, 1964; Taylor, 1958; Winnick \& Ellner, 1965; Winnick \& Kressel, 1965), that word recognition is greatly influenced by any variable that guarantees awareness of the physical characteristics of words, as well as by those that increase response availability. Verbal learning, on the other hand, seems more strongly influenced by the meaning (associative) characteristics of words. The present study has pursued this suggested relationship be presenting two kinds of familiarization tasks preceding the measurement of tachistoscopic recognition thresholds, paired-associate learning (PAL) and free-recall learning (FRL). The first familiarization task required that Ss examine eight- and nine-letter words in order to make up smaller words out of their component letters. It was expected that this procedure, necessitating scrutiny of the elements of the word, would aid in subsequent recognition but have less influence upon PAL and FRL. By contrast, the second familiarization procedure, requiring $\mathrm{Ss}$ to search for associates for the words, was predicted to be of aid in PAL and FRL, but to have less effect upon tachistoscopic recognition.

\section{SUBJECTS}

All experiments used as Ss undergraduate students from summer-session courses in introductory psychology; all served on a voluntary basis. There were $40 \mathrm{Ss}$ in each experiment, 20 serving in each of two groups.

\section{MATERIALS}

The three experiments used identical materials: 12 eight- or nine-letter nouns of low frequency (one per million) based on Thorndike-Lorge (1944) counts. Preliminary study indicated that a minimum of 20 smaller words could be constructed out of each of the experimental words (one familiarization task) and that associates were easily available (the second familiarization task). Of the 12 words, 6 were farmiliarized and 6 were control words; these were interchanged in two subgroups in each experiment. For Experiment 2, the words were paired with nonsense syllables of $47 \%$ associative value to form nonsense syllable-word pairs for PAL. APPARATUS

In Experiment 1, the words (experimental and control) were typewritten in capital letters on cards for exposure in a Gerbrands tachistoscope. Experiment 2 presented nonsense syllable-word pairs in a long-arm memory drum, and Experiment 3 used the same apparatus to present the words for FRL.

\section{EXPERIMENTAL DESIGN}

All experiments used a "mixed" arrangement of variables, with type of familiarization a "between-Ss" effect and type of word (familiarized or control) a "within-Ss" effect.

\section{PROCEDURE}

There were two stages in each of the three experiments. The first, or familiarization, stage required Ss in Group $A$ to make up as many words as possible from the letters of the six experimental words; $1 \mathrm{~min}$ was allotted per word. In Group B, the familiarization requirement was that $S s$ write down as many associates as possible to the experimental words; again, the time limit was $1 \mathrm{~min}$ per word. For the familiarization task, the words were dittoed on individual sheets of paper and stapled to form a booklet, with words randomly ordered across Ss. The second stage followed the first stage after a brief rest.
In the second stage of Experiment 1, tachistoscopic thresholds were measured for the 12 words, 6 experimental and 6 control words. Exposure intervals were begun at $.01 \mathrm{sec}$ and increased by $.005-\mathrm{sec}$ intervals until the word was correctly identified. Order of presentation of words was randomized from $S$ to $S$.

In Experiment 2, the PA lists were learned by the standard anticipation method, with stimulus items presented for $2 \mathrm{sec}$, followed by a 2 -sec exposure of stimulus plus response items; there was an 8-sec intertrial interval. For each list, four different arrangements were employed to prevent serial learning. Standard anticipation instructions were used, and learning was carried out to a criterion of one errorless trial.

Experiment 3 used the FRI method, with lists presented at a $2-\sec$ rate. Each list presentation was followed by an attempt at oral recall of the words. Leaming and recall trials were altemated until $100 \%$ correct recall was achieved.

\section{RESULTS}

Tachistoscopic Thresholds

The mean thresholds for the two kinds of familiarized words and for the control words are shown in Table 1. The small difference in the thresholds for familiarized words, $21.2 \mathrm{msec}$ for Group A (making new words) compared to $23.6 \mathrm{msec}$ for Group B (forming associates), is in line with the prediction. However, since the differences in thresholds for control words in the four groups parallel this difference, it is as likely that the difference stems from group differences as from an effect of the experimental variable. In the analysis of variance, only the main difference between familiarized and control words was found to be significant $[F(1,38)=7.52, p<.01]$. There was no significance in the

\section{Table 1}

Mean Tachistoscopic Thresholds (Msec) for Familiarized Words and Control Words in the Two Groups in Experiment 1

\begin{tabular}{lccc}
\hline & & Familiarized & Control \\
\hline Group A & 1 & 23.34 & 59.43 \\
Making New & & & \\
Words & 2 & 19.01 & 31.33 \\
Group B & 1 & 24.67 & 50.66 \\
Associations & 2 & 22.66 & 53.16 \\
\hline
\end{tabular}

Table 2

Mean Trials to Criterion for the PA Leaming of Familiarized and Control Words in Two Groups in Experiment 2

\begin{tabular}{lccc}
\hline & Familiarized & Control \\
\hline Group A & 1 & 13.20 & 12.30 \\
Making New Words & 2 & 22.40 & 20.30 \\
Group B & 1 & 18.00 & 15.80 \\
Associations & 2 & 16.30 & 14.80 \\
\hline
\end{tabular}


Table 3

Mean Trials to Criterion for Familiarized and Control Words in the FR Leaming of Experiment 3

\begin{tabular}{lccc}
\hline & Familiarized & Control \\
\hline Group A & 1 & 4.2 & 3.9 \\
Making New Words & 2 & 4.3 & 4.3 \\
Group B & 1 & 2.9 & 4.9 \\
Associations & 2 & 2.7 & 3.7 \\
\hline
\end{tabular}

Table 4

Mean Number Correct on First Trial for Familiarized and Control Words in the Free Recall Leaming of Experiment 3

\begin{tabular}{lccc}
\hline & & Familiarized & Control \\
\hline Group A & 1 & 4.1 & 3.5 \\
Making New Words & 2 & 4.5 & 2.5 \\
Group B & 1 & 4.9 & 2.8 \\
Associations & 2 & 4.9 & 2.8 \\
\hline
\end{tabular}

Familiarization Method by Word Type interaction $(F<1.00)$.

Paired-Associate Learning

Scores for total PAL were very similar for the two groups. Group A learned the list with a mean of 19.75 trials, while the mean for Group B was $22.45, t(38)=1.53$, $\mathrm{p}>.05$.

Table 2 shows, for the two groups, the mean trials to reach criterion for the two types of familiarized words and for the control words. The trend apparent in these data is for familiarized words in all groups to take longer to learn than did corresponding control words. Analysis of variance of the data, however, found the familiarization-control comparison to fall short of an acceptable significance level $[F(1,38)=3.52, p>.05]$. Examination of the learning curves showed both forms of familiarization to yield a small advantage in the initial stages of PAL. This advantage was lost fairly rapidly in both groups, however. Free-Recall Learning

Mean trials to reach criterion for the FRL of Experiment 3 were 5.65 in Group A and 5.00 in Group B. This small, nonsignificant advantage of Group B; whose familiarization activity consisted of finding associates for the experimental words, is in line with the prediction. The separate trials-to-criterion data for familiarized and control words, shown in Table 3 , give evidence of an interaction between the familiarization-control comparison and the type of familiarization. For Group A, the familiarized words took very slightly longer to learn than did control words; by contrast, in Group B the mean trials to criterion for the familiarized words were less than those for the control words. Analysis of variance, however, found the Familiarized-control by Type of Familiarization interaction to fall short of significance at an acceptable level $[F(1,38)=3.57, p>.05]$.
Indicating the initial advantage of both kinds of familiarized words, the numbers of words of each type recalled on the first trial are shown in Table 4. Here it can be seen that the predifferentiated words of both types had the advantage, with the relative advantage greater in Group B than in Group A. Analysis of variance of these data found no significance in overall Group A/Group B learning $(F<1.0)$. There was significance in the - ain effect of familiarization $[F(1,38) \quad 6, p<.01]$, and in the Familiariza by Group interaction $[F(1,38)=4.6, \quad .05]$. This significant interaction stems from the greater experimental-control difference in Group B than in Group A and is in line with the prediction.

\section{DISCUSSION}

The two familiarization tasks have undoubtedly instigated slightly different kinds of implicit and overt behavior. The making of words out of the letters of the experimental items required persistent scanning of individual letters. The necessary written responses bore no associative relationship to the experimental words though they were made up of some of the same letters. The association task required no more than an initial scan of the experimental words, but depended upon a kind of cognitive scanning of the meaning and experiential referents of each word. Paired with this search was of ten a vocal or subvocal repetition of the words. The required written response, of course, bore an associative relationship to the word and contributed to an associative network for each word.

For the measurement of tachistoscopic thresholds, both kinds of familiarization exerted a positive influence; that is, tachistoscopic thresholds were lower for words out of which other words had been formed and for words for which associates had been found, in comparison to control words that had not been seen before. That the finding of associates for the experimental words was of advantage is likely to derive from an effect of this procedure that differs from the word-making effect. The search for associates of the experimental words seemed to involve subvocal repetition of the words. In fact, many Ss in this group actually repeated these words aloud. Either form of repetition, of course, heightens the availability of responses, a variable found to exert a potent influence upon tachistoscopic thresholds (Winnick \& Nachbar, 1967).

On the first trial of FRL and early in PAL, both types of familiarized words showed an initial advantage over control words. On the first trial of FRL, there was a significantly greater advantage for the procedure of Group B, requiring the finding of associates.
It seems quite possible that with the small number of experimental words used, falling within the memory span, a categorizing of the experimental words as "old" words might be the basis for the initial recall superiority of the experimental words. This kind of categorization seems to be what Cofer \& Bruce $(1965$, p. 388$)$ refer to in expressing doubt that "... categorized but unassociated words will cluster." At any rate, this categorizing for FRL had to give way on subsequent trials to some other organizational basis that could include all of the items, new as well as old. Apparently, the associates formed by Group B provided slightly better basis for this organization than did the familiarization procedure of Group A, as indicated by Group B's somewhat faster learning of the list.

In PAL, the finding of associates apparently was of no aid to the associative stage in Group B. Although, as for FRL, the six experimental words could be grouped as "old" words, interference must have developed in the search for a basis for associating these items with nonsense syllables. Evidently, the associations given to the words during pretraining were not helpful in trying to link them with nonsense syllables. It seems quite possible that in such a pairing it is the characteristics of the nonsense syllables, rather than of the words, that dictate the basis for the associative linkage.

\section{REFERENCES}

COFER, C. N., \& BR UCE, D. R.Form-class as the basis for clustering in the recall of nonassociated words. Journal of Verbal Learning \& Verbal Behavior, 1965, 4, 386-389.

GIBSON, E. J., BISHOP, C. H., SCHIFF, W., \& SMITH, J. Comparison of meaningfulness and pronunciability or grouping principles in the perception and retention of verbal materials. Journal of Experimental Psychology, 1964, 67, 173-182.

TAYLOR, J. A. Meaning, frequency and visual duration thresholds. Journal of Experimental Psychology, 1958, 55, 329-333.

THORNDIKE, E. L., \& LORGE, I. The teacher's word book of 30,000 words. New York: Teacher's College, Columbia University, Bureau of Publications, 1944.

WINNICK, W. A., \& ELLNER, M. "Meaningfulness" in tachistoscopic thresholds, serial leaming, and association measurement. Psychonomic Science, 1965, 2, 233-234.

WINNICK, W. A., \& KRESSEL, K. Tachistoscopic recognition thresholds, paired-associate learning, and free recall as a function of abstractness-concreteness and word frequency. Journal of Experimental Psychology, 1965, 70, 163-168.

WINNICK, W. A., \& NACHBAR, S. Tachistoscopic recognition thresholds following paired-associate leaming. Joumal of Verbal Learning \& Verbal Behavior, 1967, 6, 95-100. NOTE

1. Supported by Grant MH 11580-02 from the National Institutes of Health, entitled "Studies of verbal learning and word recognition." 